\title{
Pre- and postoperative postural regulation following anterior cruciate ligament reconstruction
}

\author{
Thomas Bartels', Kay Brehme', Martin Pyschik', Stephan Schulze ${ }^{2}$, Karl-Stefan Delank², Georg Fieseler ${ }^{3}$, Kevin G. Laudner $^{4}$, \\ Souhail Hermassi ${ }^{5}$, René Schwesig'** \\ 'SportsClinic Halle, Center of Joint Surgery, Halle, Germany \\ ${ }^{2}$ Department of Orthopedic and Trauma Surgery, Martin-Luther University Halle-Wittenberg, Halle, Germany \\ ${ }^{3}$ Division for Shoulder Surgery and Sports Medicine, Helios Clinic Warburg, Warburg, Germany \\ ${ }^{4}$ School of Kinesiology and Recreation, Illinois State University, Normal, IL, USA \\ ${ }^{5}$ Research Unit (UR17JS01) Sport Performance, Health \& Society, Sport Performance \& Health, Higher Institute of Sport and Physical Education, Ksar-Saîd, University of “La \\ Manouba," Tunis, Tunisia
}

There are currently no longitudinal data describing the pre- and postoperative postural regulation and stability of patients with anterior cruciate ligament (ACL) damage. Therefore, the aim of this study was to evaluate postural regulation and stability prior to and during rehabilitation following surgery of the ACL. Fifty-four physically active subjects (age: $30.5 \pm 10.9$ years, 29 male subjects) were examined with the Interactive Balance System pre-, 6, and at 12 weeks following surgical reconstruction of the ACL using a hamstring tendon graft. The average period of time from injury to surgery was 27 days. Data were calculated with unifactorial and univariate analysis of variance. Significant effects were found for the somatosensory system $\left(\eta^{2}=0.115\right)$, stability indicator $\left(\eta^{2}=0.123\right)$, weight distribution index $\left(\eta^{2}=0.176\right)$, and synchronization (foot coordination) $\left(\eta^{2}=0.249\right)$. Involved side weight distribution (parameter: left) increased significantly (patients with left-sided/right-sided in- jury: $\left.\eta^{2}=0.234 / 0.272\right)$. Load distribution to the heel remained stable during all three examination periods $\left(\eta^{2}=0.035\right.$ and $\left.\eta^{2}=0.071\right)$, although a remarkable load at forefoot was observed. In seven out of 10 parameters partial effects were seen during the first 6 weeks after surgery. The results of this study indicated that injury of the $A C L$ and subsequent surgical reconstructions result in postural regulation, with improvements in somatosensory system function, postural stability, weight distribution index, and foot coordination. Also, overloading of the injured side on the feet reduces significantly during rehabilitation. Thus, the initial phase of rehabilitation (weeks 1 to 6) seems to be more effective than the second period (weeks 6 to 12) postoperatively.

Keywords: ACL reconstruction, Posturography, Knee surgery, Postural control, Rehabilitation

\section{INTRODUCTION}

Postural control requires a complex integration of sensory motor performance and can be altered by motor control anticipation, sensory taping and central recognition of balance-related physical influences, as well motion-related changes of the body's center of gravity (Di Stasi et al., 2013; Herrington et al., 2009; Lee et al., 2015; Padua et al., 2015). Soft tissue injuries, such as anterior cruciate ligament (ACL) tears, can negatively influence postural control, as well as mechanical stability and somatosensory function (Diermann et al., 2009; Fremerey et al., 2000; Fulton et al.,
2014; Ordahan et al., 2015). This reduction in postural stability can then lead to a higher risk for secondary damage resulting in a pathological cycle (Fremerey et al., 2000; Fremerey ert al., 2006; Fulton et al., 2014; Paterno et al., 2010; Wright et al., 2007).

The effect of a torn ACL as a sensory defect linked to postural control is still not completely understood. However, there is evidence that the ACL plays a major role in proprioceptive regulation of the knee joint (Campbell et al., 2012; Fremerey et al., 2000; Friemert et al., 2010; Konishi, 2011; Krogsgaard et al., 2011; Rao and Donoghue, 2014; Sarwary et al., 2015). More specifically, it is responsible for feedback regarding joint position
*Corresponding author: René Schwesig (D) https://orcid.org/0000-0002-1179-9933 Department of Orthopaedic and Trauma Surgery, Martin-Luther-University HalleWittenberg, 06120 Halle/Saale, Germany

Tel: +49-345-5571317, Fax: +49-345-5574899, E-mail: rene.schwesig@uk-halle.de Received: December 19, 2017 / Accepted: January 23, 2018
This is an Open Access article distributed under the terms of the Creative Commons Attribution Non-Commercial License (http://creativecommons.org/licenses/by-nc/4.0/) which permits unrestricted non-commercial use, distribution, and reproduction in any medium, provided the original work is properly cited. 
sense and motion detection (Aydoğ et al., 2006). Because different central sensorimotor systems (visual, vestibular, and somatosensory) are involved in neuromuscular stability (Finley et al., 2012; Friemert et al., 2010; Taube et al., 2006), any disruption of this stability requires specialized knowledge of these subsystems (Haas et al., 2006; Reed-Jones and Vallis, 2007).

Electromyographic studies have shown altered arbitrary activity after ACL-tear, as well as partial neurological paresis (Laube, 2004). Patients with insufficient proprioceptive feedback mechanisms have reduced function and motor control during activity (Reed-Jones and Vallis, 2007). Strong interactions between these sensory inputs make it difficult to determine the relative contribution of each single system. Thus, specific preferential disturbances need to be investigated (Höhne et al., 2011; Nagy et al., 2004; Steinberg et al., 2016).

Vavken et al. (2008) reported that there are no evidence based postural data during the postsurgical rehabilitation of the ACL. Currently there is a lack of evidence based data describing preand postoperative altered postural regulation and stability. Overall, the importance of the ACL as the anatomic unit for proprioceptive regulation and joint stability is still unknown. However, the success of a postoperative rehabilitation is strongly related to the time necessary for a patient to return pre-injury status (Bartels et al., 2016; Bizzini and Silvers, 2014; Petersen et al., 2014).

The purpose of this study was to compare the postural regulation and stability characteristics of participants with ACL tears based on preoperative, 6 weeks postoperative, and 12 weeks postoperative testing. It was hypothesized that postural regulation and stability would be influenced by ACL rupture, surgery and the rehabilitation process. The following specific hypotheses were tested: (a) due to ACL damage and subsequent surgery, postural stability will be decreased, (b) weight distribution (lateral and anterior-posterior) and foot coordination will be strongly unbalanced due to ACL rupture and surgery, (c) based on the sensorimotor characteristics of the rehabilitation process, the somatosensory subsystem will show the largest improvements, and (d) ACL rupture and surgery will be responsible for a reduced performance of the postural subsystems.

\section{MATERIALS AND METHODS}

\section{Design}

In accordance with Lee et al. (2015) this longitudinal study included all candidates for ACL reconstruction with a primary isolated ACL tear confirmed by magnetic resonance imaging (MRI) and physical examination (positive anterior drawer, Lachman, and/ or pivot shift tests [more than grade II]). Acute tears were defined as subjects who underwent surgery less than 3 months after injury, while chronic tears included those who underwent surgery 3 months or more following injury. The distinction was made only for the sample description. Patients with concomitant meniscus tear were excluded to eliminate bias resulting from meniscus tear. Patients with bilateral ACL injuries or associated injuries to any other ligament (i.e., the medial or lateral collateral ligament or the posterior cruciate ligament), previous injury/surgery to either knee, or any associated extra-articular lesions were excluded as well. Patients were also excluded if they were unable to perform the postural stability tests due to pain or limited motion of the knee joint. Forty-two subjects were classified as having acute ACL tears, while 12 were classified as chronic tears. The baseline demographic characteristics of the two groups were similar except for Body mass index (Table 1).

Postural regulation and stability were assessed with the Interactive Balance System (IBS). This system has a comprehensive reference database stratified by age and gender has already been published (Schwesig et al., 2013). Therefore, we were able to check

Table 1. Demographic characteristics of subjects with acute and chronic anterior cruciate ligament (ACL) tears

\begin{tabular}{lcccc}
\hline Variable & Acute ACL group $(\mathrm{n}=42)$ & Chronic ACL group $(\mathrm{n}=12)$ & $P$-value & $\eta^{2}$ \\
\hline Sex, male:female & $22: 20$ & $7: 5$ & 0.715 & $0.133^{\dagger}$ \\
Laterality, left:right & $18: 24$ & $6: 6$ & 0.661 & $0.193^{\dagger}$ \\
Age $(\mathrm{yr})$ & $30.3 \pm 11.4(12.6-60.7)$ & $31.2 \pm 9.18(16.5-44.7)$ & 0.797 & 0.001 \\
Height $(\mathrm{m})$ & $1.77 \pm 0.10(1.54-1.99)$ & $1.79 \pm 0.10(1.63-1.90)$ & 0.532 & 0.008 \\
Weight $(\mathrm{kg})$ & $77.2 \pm 16.5(48.1-107.8)$ & $87.8 \pm 16.0(61.4-132.0)$ & 0.053 & 0.070 \\
Body mass index $\left(\mathrm{kg} / \mathrm{m}^{2}\right)$ & $24.5 \pm 3.75(17.9-32.0)$ & $27.4 \pm 3.73(23.3-34.3)$ & $0.023^{*}$ & 0.095 \\
Time interval trauma vs. surgery (day) & $50.2 \pm 78.9(3-395)$ & $325.0 \pm 711.0(6-2,555)$ & $0.015^{*}$ & \\
\hline
\end{tabular}

Values are presented as mean \pm standard deviation (range).

${ }^{*} P<0.05$, significant differences. ${ }^{\dagger}$ Chi-quadrat. 


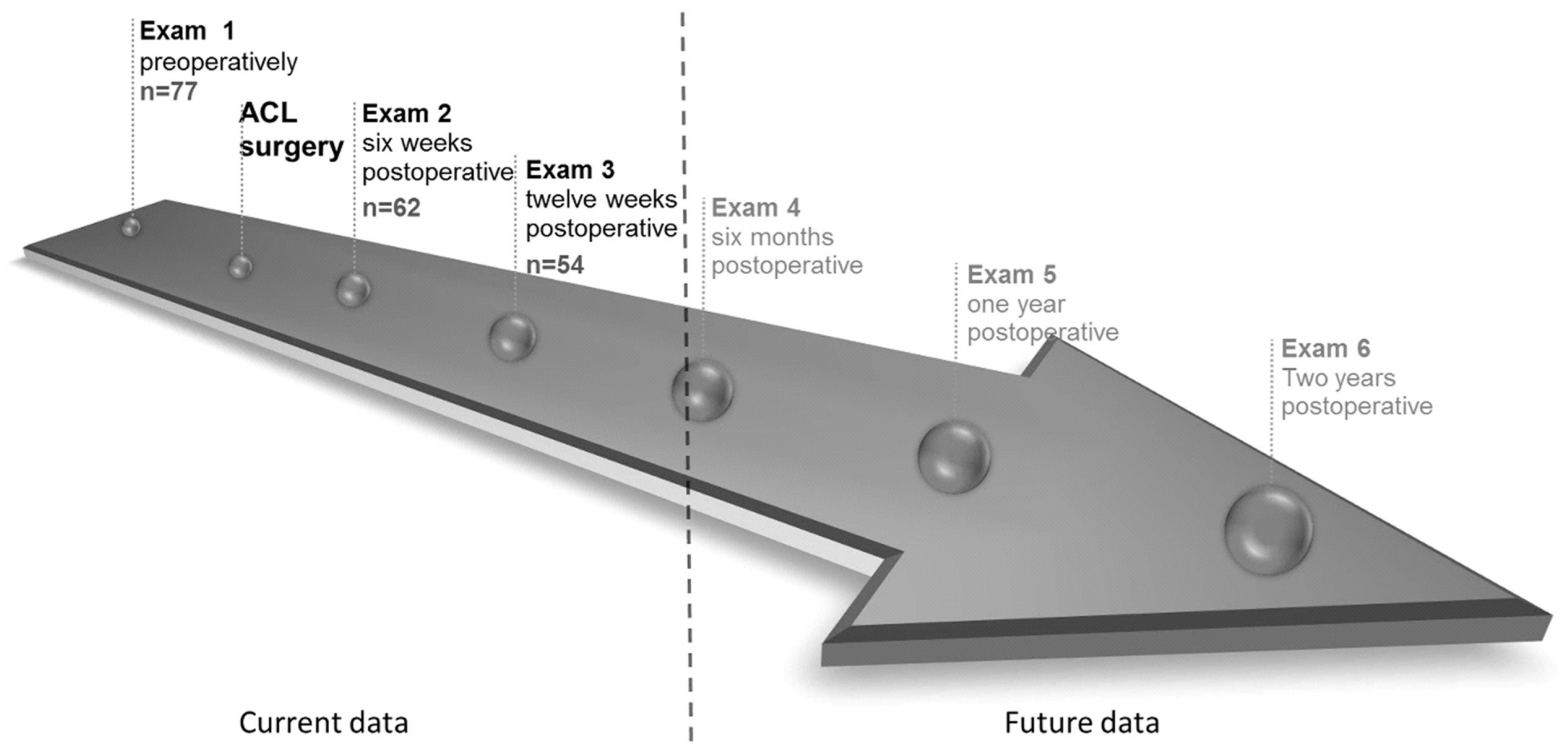

Fig. 1. Flow chart of the longitudinal study design. ACL, anterior cruciate ligament.

our data by a comparable sample of reference data (age group: 30 40 years). For this reason, recruitment of an asymptomatic control group was not necessary. The reference data also corresponds to the pre-injury state of normal healthy subjects.

\section{Subjects}

Seventy-seven subjects ( 30 female, 44 male subjects; age: $31.5 \pm 11.3$ years; range, $13-68$ years; body height, $1.77 \pm 0.09 \mathrm{~m}$; body mass, $80.7 \pm 16.4 \mathrm{~kg}$; body mass index, $25.5 \pm 3.97 \mathrm{~kg} / \mathrm{m}$ ) volunteered to participate in this study. All participants provided their written consent to participate in this study after being informed of all procedures and risks. A parental or guardian consent for all young patients (age under 18 years) involved in this investigation was obtained. The patients were diagnosed with an ACL lesion verified by MRI and physical examination performed by an orthopedic surgeon. Forty-two patients (55\%) had a right-sided ACL injury. Most of these tears occurred during participation during a team sport $(54 \%)$ or skiing $(26 \%)$. The average period from time of injury to surgery was 27 days with a significant difference $(P=0.015)$ between acute and chronic ACL group (Table 1).

Fifty-four of the initial 77 participants (70\%) (25 female, 29 male subjects; age, $30.5 \pm 10.9$ years; range, $13-61$ years; body height, $1.77 \pm 0.10 \mathrm{~m}$; body mass, $79.5 \pm 16.9 \mathrm{~kg}$; body mass index, $25.2 \pm 3.90 \mathrm{~kg} / \mathrm{m}$ ) completed all examinations and underwent the standardized rehabilitative program. Therefore, the data from these 54 participants were used for analysis.

\section{Measurements}

Each participant underwent clinical investigation and three measurements with the IBS (Neurodata, Vienna, Austria) (preoperatively, 6 weeks after surgery, 12 weeks after surgery) (Fig. 1). Patients were assessed initially and then again 6 month postoperatively, as well as one and 2 years postoperatively in order to evaluate the entire rehabilitation process. All measurements were performed at the same time of day and in a quiet room to minimize any disruptions during testing.

The IBS system consists of four independent force plates (Fig. 2) supporting the heels and forefeet in order to measure postural regulation (sampling rate, $32 \mathrm{~Hz}$ ). Postural regulation was measured as: stability indicator (general postural stability), weight distribution index, and synchronization (foot coordination measured as relationship of vibration patterns between plates). Sway intensities at different frequency ranges were determined by fast fourier transformation (FFT) of the postural sway waves (Table 2A, B).

Postural subsystems were associated with different functional frequency bands (F1, F2-4, F5-6, F7-8) (Table 2) and have been previously validated by numerous studies (Friedrich et al., 2008; Oppenheim et al., 1999; Schwesig et al., 2009; Schwesig et al., 2011). For example the frequency band 0.01 to $0.03 \mathrm{~Hz}$ (F1) was validated using samples of healthy controls $(n=52)$, Parkinson disease $(n=52)$ and cerebellar disease patients $(n=52)$. Variance analysis of the Parkinson group and control group revealed the largest differences in frequency range F1 or the visual and ni- 


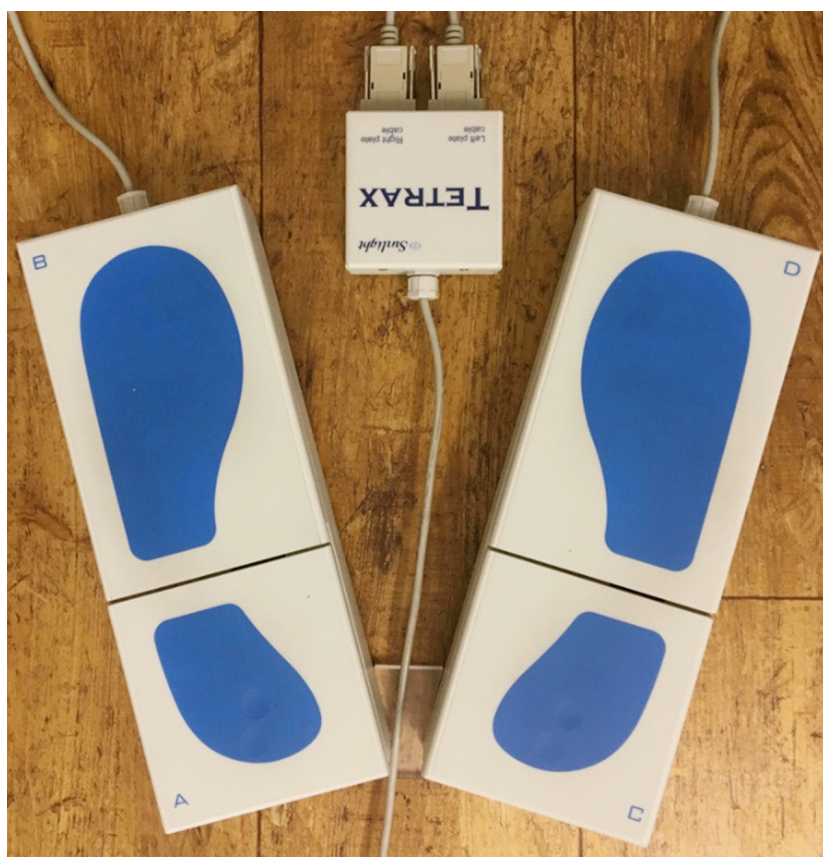

Fig. 2. Interactive Balance System consisting of four independent force plates.

Table 2A. Posturographic testing: test positions (NO-HF)

\begin{tabular}{llll}
\hline Abbreviation & Standing position & \multicolumn{1}{c}{ Head position } & Eye position \\
\hline NO & Without foam pads & Head straight & Eyes open \\
NC & Without foam pads & Head straight & Eyes closed \\
PO & On foam pads & Head straight & Eyes open \\
PC & On foam pads & Head straight & Eyes closed \\
HR & Without foam pads & Head rotate $45^{\circ}$ to the right & Eyes closed \\
HL & Without foam pads & Head rotate $45^{\circ}$ to the left & Eyes closed \\
HB & Without foam pads & Head up (dorso-flexed) & Eyes closed \\
HF & Without foam pads & Head down (ventro-flexed) & Eyes closed \\
\hline
\end{tabular}

grostriatal system (Schwesig et al., 2009). Other studies (Friedrich et al., 2008) have compared visually impaired subjects $(n=52)$ and subjects with normal vision $(n=52)$ based on IBS. The visually impaired and the control group differed significantly in the frequency range $\mathrm{F} 1(P=0.002)$. Consequently, the IBS is able to predict, but not measure, these risk factors by a FFT of sway in an indirect way.

All parameters (exceptions: heel and left) used in the IBS are dimensionless values. Instructions for the subjects' positions, frequency bands, and parameters of motor output (including interpretation) used in the IBS are explained in Table 2 (Schwesig et al., 2017). Subjects were tested during a single trial (32 sec) under eight standardized test conditions (Table 2, Fig. 3). Each person was asked to stand upright, without shoes, on two force plates with and without pads, as stable as possible but without rigidity, and constantly look at a defined object in the horizontal plane (Schwesig et al., 2013).

The IBS has been tested for reliability (Schwesig et al., 2017) and has reference data for asymptomatic subjects (Schwesig et al., 2013). In accordance with these reliability studies (Schwesig et al., 2017), we also used the mean values obtained in the eight test positions for all parameters. The study was approved by the local ethics committee (approval number: 2016-144).

All surgical procedures were performed by two experienced knee surgeons. A quadruple bundled hamstring-transplant (tendon of the semitendinosus muscle) with hybrid fixation and femoral bone-wedge technique was used for all participants to provide high pull-out strength (Weiler et al., 2001).

All participants completed the same rehabilitation protocol. This protocol was divided into four phases (Table 3).

Table 2B. Posturographic testing: parameters

\begin{tabular}{|c|c|c|}
\hline Abbreviation & Designation & Description \\
\hline \multicolumn{3}{|c|}{ Process parameters } \\
\hline F1 & Frequency band $1(0.01-0.03$ Hz) & Visual and nigrostriatal system \\
\hline F2-4 & Frequency band $2-4(0.03-0.5 \mathrm{~Hz})$ & Peripheral-vestibular system \\
\hline F5-6 & Frequency band 5-6 $(0.5-1.0 \mathrm{~Hz})$ & Somatosensory system \\
\hline F7-8 & Frequency band 7-8 (>1.0 Hz) & Cerebellar system \\
\hline \multicolumn{3}{|c|}{ Parameters of motor output } \\
\hline ST & Stability indicator & $\begin{array}{l}\text { Root mean square of successive differences of pressure signals; describes the postural stability state; } \\
\text { the greater ST, the greater instability }\end{array}$ \\
\hline WDI & Weight distribution index & $\begin{array}{l}\text { Standard deviation of the weight distribution score assuming equal weight distribution on each plate } \\
\text { (25\% per plate). }\end{array}$ \\
\hline Synch & Synchronization & $\begin{array}{l}\text { Six values describing the relationship of vibration patterns between plates calculated as scalar product; } \\
1,000 \text { - complete coactivity; }-1,000 \text { - complete compensation, } 0 \text { - no coactivity or compensation }\end{array}$ \\
\hline Heel & Forefoot-hindfoot ratio & Percentage of weight distribution forefoot vs. hindfoot with description of heel loading. \\
\hline Left & Left side & Percentage of weight distribution left vs. right with description of left side loading \\
\hline
\end{tabular}




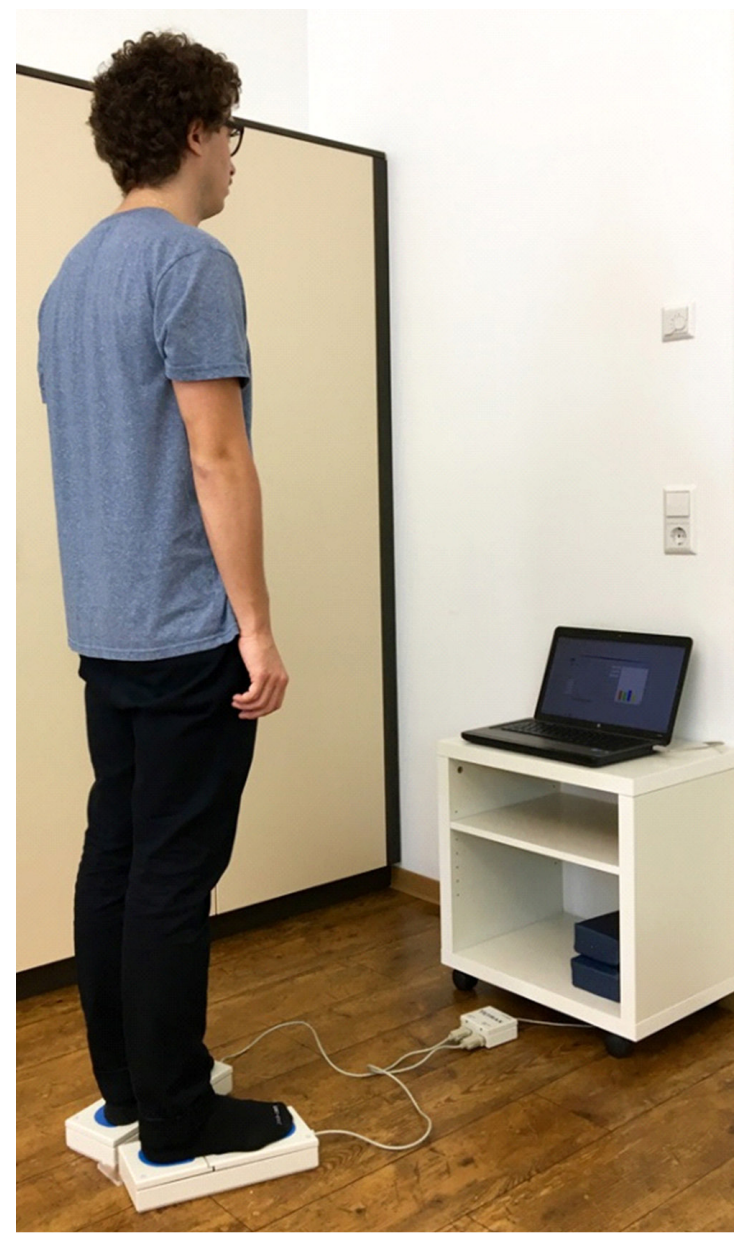

Fig. 3. Assessment of postural regulation and stability characteristics using Interactive Balance System.

\section{Statistics}

An a priori power analysis (nQuery 4.0, Statistical solutions Ltd., Cork, Ireland) was performed to determine the sample size using a two-sided hypothesis test at an alpha level of 0.05 and a power of 0.8 . The results of this pilot study indicated that 54 knees would be required to detect a significant mean difference of 3 (main parameter: stability indicator). Taking into account a dropout rate of $30 \%$, we recruited 77 patients with ACL rupture initially.

Descriptive statistics, including means, standard deviations, minimums and maximums were ascertained for all parameters (e.g., synchronization, stability indicator, frequency band 1). The comparison of all pre and postexaminations were calculated with a univariate model using analyse of variance. Furthermore we calculated total effects for all parameters and over all three examinations using a general linear model. The critical level of signifi-
Table 3. Phases of rehabilitation

\begin{tabular}{|c|c|c|}
\hline Phase & Week & Goals and content \\
\hline \multirow[t]{6}{*}{1} & $1-2$ & Goal: pain relief, no effusion, pain free range of motion (ROM) \\
\hline & & Constant support with an orthesis for full leg extension \\
\hline & & Partial weight bearing with crutches $(30 \mathrm{~kg})$ \\
\hline & & Lymph drainage 2-3 times per week \\
\hline & & $\begin{array}{l}\text { Isometric exercises with special regard to knee extension } \\
\text { ROM }\end{array}$ \\
\hline & & $\begin{array}{l}\text { Electrotherapy of the thigh muscles for improvement of } \\
\text { neuromuscular sensitivity }\end{array}$ \\
\hline \multirow[t]{4}{*}{2} & $3-6$ & $\begin{array}{l}\text { Goal: pain free full ROM, full weight bearing, safe muscular } \\
\text { stabilization of knee joint }\end{array}$ \\
\hline & & Support with orthesis \\
\hline & & Lymph drainage \\
\hline & & $\begin{array}{l}\text { Physiotherapy (sensorimotor training, axial leg training, } \\
\text { patella mobilization, myofascial techniques, stretching) }\end{array}$ \\
\hline \multirow[t]{3}{*}{3} & $7-12$ & Goal: recovery of full general function \\
\hline & & Intense rehabilitation in clinic or institution \\
\hline & & Physiotherapy and sports therapy (strength and endurance) \\
\hline \multirow[t]{3}{*}{4} & $13-20$ & Goal: recovery of sports-specific function \\
\hline & & Running exercises (treadmill) \\
\hline & & Successive sports-specific training \\
\hline
\end{tabular}

cance was adjusted using the Bonferroni correction. After applying a Bonferroni correction, significance level $(P)$ of 0.05 divided by the number of tests (9), differences between means were considered as being statistically significant if $P$-values were $<0.006$ or partial eta-square $\left(\eta^{2}\right)$ values were greater than 0.10 . Partial etasquare $\left(\eta^{2}\right)$ values were provided to represent the level of clinical significance (Vincent, 2005). All statistical analyses were performed using IBM SPSS Statistics ver. 25.0 (IBM Co., Armonk, NY, USA)

\section{RESULTS}

We found significant longitudinal improvements in four (somatosensory system, stability indicator, weight distribution index, and synchronization) parameters (Table 4). The frequency range F5-6 (somatosensory system) was the only postural subsystem that changed. The largest improvement in the somatosensory performance was observed between preoperative and 6 weeks postoperative $\left(\eta^{2}=0.108\right)$. The same improvements in performance, between pre and 6 weeks postoperative testing, were detected for the stability indicator $\left(\eta^{2}=0.100\right)$ and weight distribution index $\left(\eta^{2}=0.123\right)$. Synchronization was the parameter with the largest improvement over the total time of examination (12 weeks). Improvements in synchronization were found between 
Table 4. Descriptive comparison of two examinations and analysis of variance, calculation of effect size $\left(\eta^{2}\right)$ between exams 1, 2, and 3 for unilateral posturographic parameters and body mass among patients with anterior cruciate ligament injury (left and right)

\begin{tabular}{|c|c|c|c|c|c|c|}
\hline Parameter & $\begin{array}{c}\text { Exam } 1 \\
\text { (preoperative) }\end{array}$ & $\begin{array}{c}\text { Exam } 2 \\
\text { (6 weeks postoperative) }\end{array}$ & $\begin{array}{c}\text { Exam } 3 \\
\text { (12 weeks postoperative) }\end{array}$ & $P$-value & Total $\eta^{2}$ & Partial $\eta^{2}$ \\
\hline Visual \& nigrostriatal system & $17.2 \pm 5.10$ & $17.5 \pm 5.06$ & $16.9 \pm 4.16$ & 0.535 & 0.012 & - \\
\hline Peripheral-vestibular system & $9.14 \pm 2.66$ & $8.88 \pm 1.88$ & $8.52 \pm 1.92$ & 0.053 & 0.059 & - \\
\hline Somatosensory system & $3.92 \pm 1.27$ & $3.56 \pm 0.85$ & $3.49 \pm 0.74$ & $0.006^{*}$ & $0.115^{*}$ & Exam 1 vs. $2\left(0.108^{*}\right)$ \\
\hline Cerebellar system & $0.74 \pm 0.26$ & $0.71 \pm 0.16$ & $0.70 \pm 0.15$ & 0.228 & 0.028 & - \\
\hline Stability indicator & $22.8 \pm 8.57$ & $20.7 \pm 4.89$ & $19.7 \pm 4.04$ & $0.005^{*}$ & $0.123^{*}$ & Exam 1 vs. $2\left(0.100^{*}\right)$ \\
\hline Weight distribution index & $8.63 \pm 3.47$ & $7.40 \pm 2.53$ & $6.80 \pm 2.64$ & $<0.001^{*}$ & $0.176^{*}$ & Exam 1 vs. $2\left(0.123^{*}\right)$ \\
\hline Synchronization & $473 \pm 238$ & $575 \pm 151$ & $632 \pm 150$ & $<0.001^{*}$ & $0.249 *$ & $\begin{array}{l}\text { Exam } 1 \text { vs. } 2\left(0.171^{*}\right) \\
\text { Exam } 2 \text { vs. } 3\left(0.166^{*}\right)\end{array}$ \\
\hline Body mass (kg) & $79.5 \pm 16.9$ & $79.7 \pm 18.0$ & $80.1 \pm 18.0$ & 0.299 & 0.022 & - \\
\hline
\end{tabular}

Values are presented as mean \pm standard deviation.

* Significance was set at $P<0.006$ or $\eta^{2} \geq 0.10$.

Table 5. Descriptive comparison of three examinations and analysis of variance, calculation of effect size $\left(\eta^{2}\right)$ between exams 1, 2, and 3 only for bilateral posturographic parameters (left and heel) and for patients with left-sided and right-sided anterior cruciate ligament (ACL) injury separately

\begin{tabular}{|c|c|c|c|c|c|c|}
\hline Parameter & $\begin{array}{c}\text { Exam } 1 \\
\text { (preoperative) }\end{array}$ & $\begin{array}{c}\text { Exam } 2 \\
\text { (6 weeks postoperative) }\end{array}$ & $\begin{array}{c}\text { Exam } 3 \\
\text { (12 weeks postoperative) }\end{array}$ & $P$-value & Total $\eta^{2}$ & Partial $\eta^{2}$ \\
\hline \multicolumn{7}{|c|}{ Patients with left-sided ACL injury } \\
\hline Heel (\%) & $39.8 \pm 7.13$ & $38.2 \pm 6.64$ & $39.3 \pm 7.02$ & 0.417 & 0.035 & - \\
\hline \multirow[t]{2}{*}{ Left $(\%)$} & $42.6 \pm 8.55$ & $45.5 \pm 4.78$ & $46.6 \pm 4.72$ & $0.007^{*}$ & $0.234^{*}$ & Exam 1 vs. $2\left(0.170^{*}\right)$ \\
\hline & & & & & & Exam 2 vs. $3\left(0.121^{*}\right)$ \\
\hline \multicolumn{7}{|c|}{ Patients with right-sided $\mathrm{ACL}$ injury $(\mathrm{n}=30$ ) } \\
\hline Heel (\%) & $44.7 \pm 6.69$ & $42.4 \pm 5.16$ & $43.1 \pm 6.33$ & 0.128 & 0.071 & Exam 1 vs. $2(0.100)$ \\
\hline \multirow[t]{2}{*}{ Left (\%) } & $57.6 \pm 8.97$ & $53.5 \pm 4.11$ & $51.5 \pm 2.78$ & $0.001^{*}$ & $0.272^{*}$ & Exam 1 vs. $2\left(0.207^{*}\right)$ \\
\hline & & & & & & Exam 2 vs. $3(0.269 *)$ \\
\hline
\end{tabular}

Values are presented as mean \pm standard deviation.

Heel, percentage of weight distribution forefoot vs. hindfoot with description of heel loading; left, percentage of weight distribution left vs. right with description of left side loading.

*Significance was set at $P<0.006$ or $\eta^{2} \geq 0.10$

pre- and 6 weeks postoperative $\left(\eta^{2}=0.171\right)$ and between 6 weeks and 12 weeks postoperative $\left(\eta^{2}=0.166\right)$.

Regarding weight distribution to the injured/noninjured leg only weight distribution in the lateral direction was influenced (parameter left). A significant increase in load was placed on the injured side throughout the postoperative test sessions (Table 5). This effect was slightly more pronounced in the patients with right-sided ACL injury (total effect: $\eta^{2}=0.234$ vs. 0.272 ).

There were no significant differences (interaction effects) between the acute and chronic ACL tear groups concerning any posturographic parameters. The largest interaction effect was detected for the peripheral-vestibular system (F2-4) and between 6 to 12 weeks postoperative $\left(P=0.033, \eta^{2}=0.085\right)$. Moreover, there were no group differences in any postural parameters.

The anterior-posterior weight distribution was not changed in either samples over the 12 weeks. It is conspicuous that patients with left-sided ACL injury stand significantly more on the forefoot than patients with right-sided ACL injury (39\% vs. $43 \%$ ). The difference increased with the progressive rehabilitation process (exam 1, $\eta^{2}=0.047 ;$ exam 2, $\eta^{2}=0.067 ;$ exam $\left.3, \eta^{2}=0.078\right)$.

\section{DISCUSSION}

The influence of ACL-surgery on postural balance and regulation is lacking and controversial (Howells et al., 2011). In particular there are few studies that have investigated postural performance prior to and following reconstruction of the ACL. Therefore, it has remained unclear, if surgery is able to restore postural control (Palm et al., 2015). In addition previous literature has raised concerns regarding incomplete knowledge about postural 
subsystems related to neuromuscular stabilization in the lower extremities (Finley et al., 2012; Friemert et al., 2010; Peterka, 2002; Taube et al., 2006). Our investigation provides valuable information regarding the influence of ACL reconstructive surgery for reestablishing postural control. Four major findings emerge from our study: (a) rupture of the ACL has the largest influence regarding postural stability (36\%), weight distribution (difference to reference data: 69\%), and foot coordination (30\%); (b) following ACL reconstruction, we observed the largest recovery in load distribution to the injured side ( $\eta^{2}$-range, $\left.0.23-0.27\right)$ and foot coordination $\left(\eta^{2}=0.25\right)$; (c) for the postural subsystems, only the somatosensory system showed a significant improvement $\left(\eta^{2}=0.12\right)$ during the rehabilitation process; (d) the forefoot-hindfoot ratio (parameter: heel) is the only parameter that showed deterioration during the rehabilitation process. For the postural subsystems, reduction in performance ranged closely between $13 \%$ (somatosensory system) to $18 \%$ (visual/nigrostriatal system).

Brattinger et al. (2013) reported a 25\% reduction in postural stability following an ACL-tear. Other research has shown that the postural stability (stability indicator) decreases with age (36\%) among asymptomatic subjects (Schwesig et al., 2013). A deviation between $5 \%$ (heel load distribution, patients with right-sided ACL injury; $47 \%$ vs. $44.7 \%$ ) to $69 \%$ (weight distribution index; 5.11 vs. 8.63) was determined for postural performance between asymptomatic subjects (Schwesig et al., 2013) and patients following ACL-surgery. The performance of all postural subsystems was reduced as a result of ACL rupture and surgery. In contrast to the literature, which has shown multiple postulated decreases in proprioceptive capacity (Brattinger et al., 2013; Palm et al., 2015), we found the lowest reduction in the somatosensory system (13\%). Twelve weeks after surgery patients in our study achieved the same level of somatosensory function as the healthy subjects in this previous research (3.49 vs. 3.48). This partially underscores the study of Fremerey et al. (1998), when a large deterioration of proprioception occurred shortly after ACL-injury and was not able to be completely restored despite long-term and intense rehabilitation.

As expected, our subjects demonstrated an increased weight bearing ability of the injured limb throughout the rehabilitation process. However, no change was observed in anterior-posterior weight distribution. More specifically, there was an increased load distribution to the forefoot for all three testing periods. The higher load on the forefoot after ACL-tear and reconstruction is presumably a result of a quadriceps muscle avoidance pattern. Shimokochi et al. (2013) reported that patients with ACL injuries may present with an increased forward lean to assist with decreasing the anterior shear force on the ACL and subsequent activation of the quadriceps. Our findings of a greater load distribution to the forefoot would support this theory.

Palm et al. (2015) reported a 21\% increase in postural stability after an average of 608 days ACL reconstruction. The postural stability of our subjects improved by $14 \%$ after 3 months. However, differences in methodology (IBS vs. Biodex Stability System) make an actual comparison of these studies difficult. Brattinger et al. (2013) concluded that established clinical practice scores and questionnaires (i.e., Western Ontario and McMaster Universities Osteoarthritis Index, Knee injury and osteoarthritis outcome score, Knee Society Score, Lysholm Knee Scoring Scale, Visual Analogue Scale for subjective instability) are unsuitable for estimation of postural stability deficits following an ACL-injury. Clinical examination and postoperative anamnesis do not rely on a valid assessment for the postural stability after surgery, so these authors postulated the computerized dynamic posturography as the gold standard. This underscores the value of our results and supports the necessity to implement postural assessment devices in clinical practice.

A limiting factor in this examination was the small number of comparable studies. This was the first longitudinal investigation using the IBS among subjects prior to and following ACL reconstruction. This impeded the discussions on the data, but at the same time reflected the unique design of the study. Future studies are needed to establish clinical scores and assessments using a longitudinal study design to validate the new postural assessment and parameters and to enable discussions on its clinical relevance. We must also point out that the participants' rehabilitation was standardized. However, the participants' rehabilitations were not performed under the care of the investigators, so we cannot verify that each protocol was followed precisely as prescribed. The comparison of the preoperative values with reference data of the same age is limited, because of independent samples. Otherwise, it is a large advantage of the IBS to provide age and gender stratified reference data for all parameters. Future research should also address screening tests using the IBS among uninjured athletes in order to generate individual reference data.

This study demonstrates the increased postural control of patients with an ACL-tear following reconstructive surgery. In particular the postulated, but not evidence based consequences for the sensorimotor system, especially proprioception, were shown and calculated. The IBS-device offers a valuable assessment tool for determining postural regulation during ACL rehabilitation, 
even for postural subsystems. Future research should objectively and longitudinally evaluate perspective postural regulation during rehabilitation. The special value of this study is the fact that for the first time the significance of the ACL rupture as well as subsequent treatment (surgery, rehabilitation) with regard to postural regulation was investigated by means of a sufficiently large cohort in a longitudinal design. The isolated orthopedic view (flexibility, strength, pain), as it dominates so far, should be replaced by a more holistic approach.

\section{CONFLICT OF INTEREST}

No potential conflict of interest relevant to this article was reported.

\section{REFERENCES}

Aydoğ ST, Korkusuz P, Doral MN, Tetik O, Demirel HA. Decrease in the numbers of mechanoreceptors in rabbit ACL: the effects of ageing. Knee Surg Sports Traumatol Arthrosc 2006;14:325-329.

Bartels T, Proeger S, Brehme K, Pyschik M, Delank KS, Schulze S, Schwesig R, Fieseler G. The SpeedCourt system in rehabilitation after reconstruction surgery of the anterior cruciate ligament (ACL). Arch Orthop Trauma Surg 2016;136:957-966.

Bizzini M, Silvers HJ. Return to competitive football after major knee surgery: more questions than answers? J Sports Sci 2014;32:1209-1216.

Brattinger F, Stegmüller B, Riesner HJ, Friemert B, Palm HG. Anterior cruciate ligament ruptures and postural control: correlation of functional knee scores with computerized dynamic posturography. Orthopade 2013;42:100-106.

Campbell AD, Chua R, Inglis JT, Carpenter MG. Startle induces early initiation of classically conditioned postural responses. J Neurophysiol 2012;108:2946-2956.

Di Stasi S, Myer GD, Hewett TE. Neuromuscular training to target deficits associated with second anterior cruciate ligament injury. J Orthop Sports Phys Ther 2013;43:777-792, A1-11.

Diermann N, Schumacher T, Schanz S, Raschke MJ, Petersen W, Zantop T. Rotational instability of the knee: internal tibial rotation under a simulated pivot shift test. Arch Orthop Trauma Surg 2009;129:353-358.

Finley JM, Dhaher YY, Perreault EJ. Contributions of feed-forward and feedback strategies at the human ankle during control of unstable loads. Exp Brain Res 2012;217:53-66.

Fremerey R, Freitag N, Wippermann B, Stalp M, Fu FH. Sensorimotor potential of the intact and injured anterior and posterior cruciate ligaments: a neurophysiological study in an animal model. Z Orthop Ihre

\section{Grenzgeb 2006;144:158-163.}

Fremerey RW, Lobenhoffer P, Born I, Tscherne H, Bosch U. Can knee joint proprioception by reconstruction of the anterior cruciate ligament be restored? A prospective longitudinal study. Unfallchirurg 1998;101:697-703.

Fremerey RW, Lobenhoffer P, Zeichen J, Skutek M, Bosch U, Tscherne H. Proprioception after rehabilitation and reconstruction in knees with deficiency of the anterior cruciate ligament: a prospective, longitudinal study. J Bone Joint Surg Br 2000;82:801-806.

Friedrich M, Grein HJ, Wicher C, Schuetze J, Mueller A, Lauenroth A, Hottenrott K, Schwesig R. Influence of pathologic and simulated visual dysfunctions on the postural system. Exp Brain Res 2008;186:305314.

Friemert B, Franke S, Gollhofer A, Claes L, Faist M. Group I afferent pathway contributes to functional knee stability. J Neurophysiol 2010;103: 616-622.

Fulton J, Wright K, Kelly M, Zebrosky B, Zanis M, Drvol C, Butler R. Injury risk is altered by previous injury: a systematic review of the literature and presentation of causative neuromuscular factors. Int J Sports Phys Ther 2014;9:583-595.

Haas CT, Buhlmann A, Turbanski S, Schmidtbleicher D. Proprioceptive and sensorimotor performance in Parkinson's disease. Res Sports Med 2006;14:273-287.

Herrington L, Hatcher J, Hatcher A, McNicholas M. A comparison of Star Excursion Balance Test reach distances between ACL deficient patients and asymptomatic controls. Knee 2009;16:149-152.

Höhne A, Stark C, Brüggemann GP, Arampatzis A. Effects of reduced plantar cutaneous afferent feedback on locomotor adjustments in dynamic stability during perturbed walking. J Biomech 2011;44:21942200.

Howells BE, Ardern CL, Webster KE. Is postural control restored following anterior cruciate ligament reconstruction? A systematic review. Knee Surg Sports Traumatol Arthrosc 2011;19:1168-1177.

Konishi YU. ACL repair might induce further abnormality of gamma loop in the intact side of the quadriceps femoris. Int J Sports Med 2011;32:292-296.

Krogsgaard MR, Fischer-Rasmussen T, Dyhre-Poulsen P. Absence of sensory function in the reconstructed anterior cruciate ligament. J Electromyogr Kinesiol 2011;21:82-86.

Laube W. Das sensomotorische System, die Bewegungsprogrammierung und die sensomotorische Koordination beim Gesunden und Verletzten. Österr Z Phys Med Rehabil 2004;14:35-49.

Lee DH, Lee JH, Ahn SE, Park MJ. Effect of time after anterior cruciate ligament tears on proprioception and postural stability. PLoS One 2015;10:e0139038. 
Nagy E, Toth K, Janositz G, Kovacs G, Feher-Kiss A, Angyan L, Horvath G. Postural control in athletes participating in an ironman triathlon. Eur J Appl Physiol 2004;92:407-413.

Oppenheim U, Kohen-Raz R, Alex D, Kohen-Raz A, Azarya M. Postural characteristics of diabetic neuropathy. Diabetes Care 1999;22:328-332.

Ordahan B, Küçükşen S, Tuncay İ, Salli A, Uğurlu H. The effect of proprioception exercises on functional status in patients with anterior cruciate ligament reconstruction. J Back Musculoskelet Rehabil 2015; 28:531-537.

Padua DA, DiStefano LJ, Beutler AI, de la Motte SJ, DiStefano MJ, Marshall SW. The landing error scoring system as a screening tool for an anterior cruciate ligament injury-prevention program in elite-youth soccer athletes. J Athl Train 2015;50:589-595.

Palm HG, Schlumpberger S, Riesner HJ, Friemert B, Lang P. Influence of anterior cruciate reconstruction on postural stability: a pre- and postoperative comparison. Unfallchirurg 2015;118:527-534.

Paterno MV, Schmitt LC, Ford KR, Rauh MJ, Myer GD, Huang B, Hewett TE. Biomechanical measures during landing and postural stability predict second anterior cruciate ligament injury after anterior cruciate ligament reconstruction and return to sport. Am J Sports Med 2010;38: 1968-1978.

Peterka RJ. Sensorimotor integration in human postural control. J Neurophysiol 2002;88:1097-1118.

Petersen W, Taheri P, Forkel P, Zantop T. Return to play following ACL reconstruction: a systematic review about strength deficits. Arch Orthop Trauma Surg 2014;134:1417-1428.

Rao NG, Donoghue JP. Cue to action processing in motor cortex populations. J Neurophysiol 2014;111:441-453.

Reed-Jones RJ, Vallis LA. Proprioceptive deficits of the lower limb following anterior cruciate ligament deficiency affect whole body steering control. Exp Brain Res 2007;182:249-260.

Sarwary AM, Stegeman DF, Selen LP, Medendorp WP. Generalization and transfer of contextual cues in motor learning. J Neurophysiol 2015; 114:1565-1576.

Schwesig R, Becker S, Lauenroth A, Kluttig A, Leuchte S, Esperer HD. A novel posturographic method to differentiate sway patterns of pa- tients with Parkinson's disease from patients with cerebellar ataxia. Biomed Tech (Berl) 2009;54:347-356.

Schwesig R, Fischer D, Kluttig A. Are there changes in postural regulation across the lifespan? Somatosens Mot Res 2013;30:167-174.

Schwesig R, Goldich Y, Hahn A, Müller A, Kohen-Raz R, Kluttig A, Morad Y. Postural control in subjects with visual impairment. Eur J Ophthalmol 2011;21:303-309.

Schwesig R, Hollstein L, Plontke SK, Delank KS, Fieseler G, Rahne T. Comparison of intraobserver single-task reliabilities of the Interactive Balance System (IBS) and Vertiguard in asymptomatic subjects. Somatosens Mot Res 2017;34:9-14.

Shimokochi Y, Ambegaonkar JP, Meyer EG, Lee SY, Shultz SJ. Changing sagittal plane body position during single-leg landings influences the risk of non-contact anterior cruciate ligament injury. Knee Surg Sports Traumatol Arthrosc 2013;21:888-897.

Steinberg N, Nemet D, Pantanowitz M, Zeev A, Hallumi M, Sindiani M, Meckel Y, Eliakim A. Longitudinal study evaluating postural balance of young athletes. Percept Mot Skills 2016;122:256-279.

Taube W, Schubert M, Gruber M, Beck S, Faist M, Gollhofer A. Direct corticospinal pathways contribute to neuromuscular control of perturbed stance. J Appl Physiol (1985) 2006;101:420-429.

Vavken P, Culen G, Dorotka R. Clinical applicability of evidence-based orthopedics--a cross-sectional study of the quality of orthopedic evidence. Z Orthop Unfall 2008;146:21-25.

Vincent JW. Statistics in kinesiology. Champaign (IL): Human Kinetics; 2005.

Weiler A, Richter M, Schmidmaier G, Kandziora F, Südkamp NP. The EndoPearl device increases fixation strength and eliminates construct slippage of hamstring tendon grafts with interference screw fixation. Arthroscopy 2001;17:353-359.

Wright RW, Dunn WR, Amendola A, Andrish JT, Bergfeld J, Kaeding CC, Marx RG, McCarty EC, Parker RD, Wolcott M, Wolf BR, Spindler KP. Risk of tearing the intact anterior cruciate ligament in the contralateral knee and rupturing the anterior cruciate ligament graft during the first 2 years after anterior cruciate ligament reconstruction: a prospective MOON cohort study. Am J Sports Med 2007;35:1131-1134. 